\title{
Nota Científica \\ Coleópteros broqueadores de madeira em ambiente natural de Mata Atlântica e em plantio de eucalipto
}

\author{
Fabricio Gomes Gonçalves ${ }^{1}$, Acácio Geraldo de Carvalho², Willian Vagner Matos Cardoso ${ }^{3}$, Cleyton dos Santos Rodrigues ${ }^{4}$ \\ ${ }^{1}$ Universidade Federal do Espírito Santo, Centro de Ciências Agrárias, Departamento de Ciências Florestais e da Madeira, Av. Governador Lindemberg, $n^{\circ} 316$, \\ Centro, CEP 29550-000, Jerônimo Monteiro, ES, Brasil \\ 2Universidade Federal Rural do Rio de Janeiro, Instituto de Florestas, Departamento de Produtos Florestais, BR 465, Km 7, Antiga Estrada Rio-São Paulo, \\ CEP 23851-970, Seropédica, RJ, Brasil \\ ${ }^{3}$ Prefeitura Municipal de Água Boa, Av. Espírito Santo, n 14, CEP 39790-000, Água Boa, MG, Brasil \\ ${ }^{4}$ Instituto Estadual de Florestas, Rua Antonio Teodolino, n 86, CEP 39680-000, Capelinha, MG, Brasil
}

*Autor correspondente:

fabricio.goncalves@ufes.br

Termos para indexação:

Madeira

Resistência natural

Armadilha etanólica

Index terms:

Wood

Natural resistence

Ethanol trap

Histórico do artigo:

Recebido em 13/03/2013

Aprovado em 15/09/2014

Publicado em 10/10/2014

doi: 10.4336/2014.pfb.34.79.499
Resumo - Objetivou-se neste trabalho fazer um levantamento de broqueadores de madeira das famílias Cerambicydae, Lyctidae, Bostrichidae, Buprestidae e subfamílias Platypodinae e Scolytinae, em ambiente natural na Mata Atlântica e em plantio de eucalipto. Instalou-se entre os meses de abril e outubro, 20 armadilhas modelo Carvalho 47 adaptado, distantes $50 \mathrm{~m}$ umas da outras. Estas foram instaladas a 1,3 $\mathrm{m}$ do solo e iscadas com etanol $\left(92,8^{\circ}\right)$, sendo cinco por ambiente: fragmento de Mata Atlântica (borda e interior); plantio de eucalipto (borda e interior). Coletou-se um total de 1.797 indivíduos, em coletas semanais matutinas. $\mathrm{O}$ talhão de eucalipto apresentou maior número de indivíduos em ambos ambientes analisados (992 indivíduos). A subfamília Scolytinae foi a mais numerosa (774 indivíduos - 43,07\%) e a mais importante do ponto de vista de deterioração da madeira. A família Bostrichidae ficou em segundo lugar em número de indivíduos, com 19,20\%, equivante a 345 indivíduos.

\section{Wood borers in natural forests and eucalypt plantation}

\begin{abstract}
The objective of this work was to survey wood borers in natural environment in the Atlantic Forest and eucalypt plantation of individuals families: Cerambicydae, Lyctidae, Bostrichidae, Buprestidae and subfamilie Platypodinae e Scolytinae. Was installed between the months of april and october, 20 Carvalho 47 traps model, adapted, baited with ethanol $\left(92.8^{\circ}\right), 50 \mathrm{~m}$ distant from each other and $1.3 \mathrm{~m}$ from the ground, with five setting: Atlantic Forest (border and interior) fragment; eucalyptus plantation (border and interior). 1,797 individuals were collected in total weekly collections and morning. The stand of eucalyptus submitted higher amounts of individuals in both setting analyzed (992 individuals). The subfamily Scolytinae was the most numerous (774 individuals $43.07 \%$ ) and the most important in terms of degradability of wood. In second place was the family Bostrichidae with 345 individuals (19.20\%).
\end{abstract}


Dentre os insetos prejudiciais às essências florestais, destacam-se aqueles conhecidos como coleobrocas, cujos danos são de extrema importância em algumas espécies florestais cultivadas, sobretudo em Eucalyptus spp.. Em ambientes florestais, seja ele natural ou cultivado, há a chance de ocorrer espécies de insetos prejudiciais, tendo em vista a existência de nichos ecológicos específicos e até mesmo de hospedeiros. Há ainda aqueles considerados agentes recicladores de biomassa vegetal (Gusmão, 2011). Determinados insetos poderão ocupar nichos específicos e se tornarem pragas esporádicas ou até mesmo obrigatórias, sendo o processo de seleção fator primordial (Marques, 1984).

Nos insetos, a ordem Coleoptera é a maior em número de espécies com hábito broqueador (Ferreira Filho et al., 2002). Compreende aqueles conhecidos como besouros, se distinguindo facilmente pela presença dos élitros. São encontrados em diferentes habitats, sendo que muitas espécies são de grande importância econômica, uma vez que podem danificar plantações e cultivos florestais (Gusmão, 2011).

Dentre os coleópteros, aqueles pertencentes ao grupo das brocas de madeira causam enormes prejuízos, tanto em madeira já abatida quanto em árvores ainda em pé. De acordo com Lelis (2000), os usuários da madeira conhecem sua vantagem como elemento construtivo, mas desconhecem ou negligenciam aspectos importantes da sua deterioração biológica. Por essa razão, não são tomadas medidas preventivas que seriam fundamentais para aumentar a vida útil da madeira e, consequentemente, reduzir os prejuízos advindos da sua deterioração.

Os coleópteros geralmente são fitófagos e predadores, mas alguns são necrófagos e outros se alimentam de fungos, sendo poucos os que são parasitas. Algumas espécies alimentam-se de folhas, outras de troncos, frutos ou raízes. Entre as diferentes famílias de coleópteros broqueadores de madeira, os insetos pertencentes à subfamília Scolytinae são os mais estudados (Carvalho et al., 1996), pois quando penetram na madeira facilitam a entrada de possíveis agentes contaminantes, sendo vetores de fungos e indiretamente causadores da seca dos ponteiros em árvores recém atacadas (Berti Filho, 1979).

O monitoramento de insetos em plantações e sistemas florestais é uma importante ferramenta do manejo integrado de pragas, pois serve para auxiliar na análise de sua flutuação populacional. Armadilhas em que se utiliza o etanol como atrativo são uma boa alternativa para o monitoramento de insetos, principalmente em povoamentos florestais e em especial para os da Ordem Coleoptera (Flechtmann et al., 1996; Abreu et al., 1997; Ferraz et al., 1999; Dorval et al., 2004; Pelentir, 2007; Murari et al., 2012). Isto se deve ao álcool, que atrai as coleobracas de forma similar à madeira, e aos produtos provenientes da fermentação dos extrativos da madeira de árvores recém abatidas ou senescentes (Trevisan et al., 2008).

Estudos que permitam verificar e quantificar a presença de insetos broqueadores em ambientes naturais e em plantios florestais, bem como a distribuição no tempo e espaço, são extremamente importantes quando se pensa em produção florestal.

$\mathrm{O}$ presente trabalho teve como objetivo identificar e quantificar coleópteros broqueadores da madeira em um fragmento de Mata Atlântica em recuperação e em um plantio florestal com híbrido clonal de Eucalyptus urophylla $\mathrm{x}$ Eucalyptus grandis.

O estudo foi realizado no Campus de São João Evangelista, pertencente ao Instituto Federal de Educação, Ciência e Tecnologia de Minas Gerais (IFETMG), Município de São João Evangelista, MG, situado na região do centro oeste mineiro, nas coordenadas $18^{\circ} 32^{\prime} 59,78^{\prime \prime} \mathrm{S}$ e $42^{\circ} 45^{\prime} 47,49^{\prime \prime} \mathrm{O}$, a $452 \mathrm{~m}$ de altitude, com uma topografia medianamente acidentada. O clima é classificado, de acordo com Köpenn, como Cwa (inverno seco e verão chuvoso), com precipitação e temperatura média anual em torno de $1.180 \mathrm{~mm}$ e $22{ }^{\circ} \mathrm{C}$, respectivamente.

Foram definidos dois ambientes principais, divididos em duas áreas: borda (limite do ambiente) e interior (50 $\mathrm{m}$ a partir da borda). O primeiro ambiente consistiu em um plantio clonal de eucalipto (Eucalyptus urophylla $\mathrm{x}$ Eucalyptus grandis), com seis anos de idade. O segundo, um ambiente de Mata Atlântica em estágio inicial de regeneração.

Foram confeccionadas armadilhas modelo Carvalho 47 (Carvalho, 1998), com algumas adaptações (Figura 1). As armadilhas constavam de uma garrafa tipo PET de $2 \mathrm{~L}$ de capacidade com abertura circular para captura dos insetos. Cada armadilha apresentava oito aberturas com diâmetro médio de $23 \mathrm{~mm}$, sendo quatro localizadas de forma oposta uma da outra. No interior da garrafa foi disposta uma mangueira plástica de $0,8 \mathrm{~cm}$ de diâmetro interno e $20 \mathrm{~cm}$ de comprimento para depósito da isca, fixada com arame, que também era usado para fixação do conjunto em campo. Utilizou-se álcool $92,8^{\circ}$ como isca atrativa. Na porção superior da garrafa foi disposto um prato plástico, com $22 \mathrm{~cm}$ de diâmetro, visando impedir a 
entrada de água proveniente de chuvas, bem como folhas, pequenos gravetos ou qualquer outro elemento estranho. Na porção inferior da armadilha foi acoplado um pote de vidro com $137 \mathrm{~mm}$ de altura e $85 \mathrm{~mm}$ de diâmetro, para armazenamento dos insetos capturados. Semanalmente, os insetos eram retirados e a isca renovada.

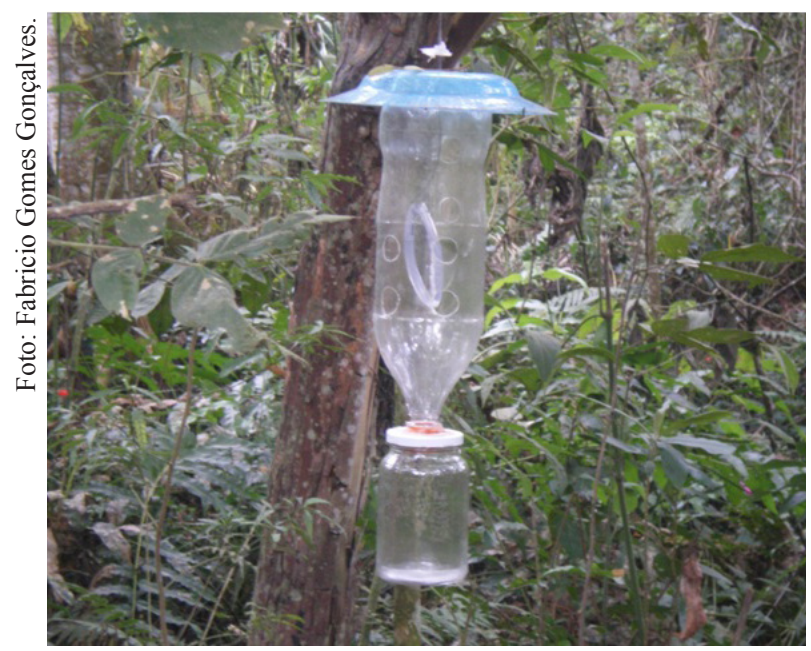

Figura 1. Armadilha etanólica modelo Carvalho 47 adaptado, instalada no interior do fragmento de Mata Atlântica em estágio inicial de regeneração.

Foram alocadas 20 armadilhas a 1,30 m do nível do solo, posicionadas aleatoriamente, a $50 \mathrm{~m}$ umas das outras, sendo cinco armadilhas por local. As coletas foram realizadas semanalmente, entre os meses de abril a outubro, sempre no período matutino, com ou sem precipitação pluviométrica.
Os insetos coletados semanalmente foram triados, quantificados e identificados ao nível de família e subfamília, conforme os ambientes avaliados. Foram identificados exclusivamente os insetos da Ordem Coleoptera, por comparação direta, com base na bibliografia existente.

Durante o período de abril a outubro foram capturados 1.797 insetos (Tabela 1), destacando-se as famílias Cerambicydae, Lyctidae, Bostrichydae, Buprestidae e as subfamílias Platypodinae e Scolytinae.

Nos ambientes estudados, notou-se que as famílias Cerambycidae, Lyctidae, Bruprestidae e a subfamília Platypodinae foram as menos expressivas, representando menos de 7,5\% dos coleópteros coletados no período. Os mais numerosos e expressivos foram, na sequência, os escolytineos e os bostriquídeos, representando cerca de $60 \%$ dos coleópteros coletados.

A frequência relativa das famílias de coleópteros avaliados nos ambientes estudados variou de 0 a $30,8 \%$, para o interior da mata, e de 0 a $37,7 \%$, para a borda da mata. No ambiente silvicultural com eucalipto, foram respectivamente de 0 a $34,6 \%$ e de 0 a $54,0 \%$, para o interior e borda do talhão. Estes números refletem a diversidade dos ambientes estudados, indicando a necessidade de melhor avaliá-los, sobretudo para as principais famílias e subfamílias.

As Figuras 2 e 3 mostram o comportamento populacional das coleobrocas para os quatro ambientes estudados.

Observou-se que no mês de agosto houve um aumento de Scolytinae em ambos ambientes de borda e no interior da área com eucalipto, exceto para o mês de julho no interior da área com eucalipto.

Tabela 1. Frequência absoluta (Fa) e relativa (Fr) de coleópteros broqueadores coletados com armadilha etanólica nos quatro ambientes estudados, em São João Evangelista, MG (abril a outubro de 2009).

\begin{tabular}{|c|c|c|c|c|c|c|c|c|c|}
\hline \multirow{4}{*}{$\begin{array}{c}\text { Família/ } \\
\text { Subfamília }\end{array}$} & \multicolumn{8}{|c|}{ Ambiente } & \multirow{4}{*}{ Total } \\
\hline & \multicolumn{4}{|c|}{ Mata } & \multicolumn{4}{|c|}{ Eucalipto } & \\
\hline & \multicolumn{2}{|c|}{ Interior } & \multicolumn{2}{|c|}{ Borda } & \multicolumn{2}{|c|}{ Interior } & \multicolumn{2}{|c|}{ Borda } & \\
\hline & $\mathbf{F a}$ & $\operatorname{Fr}(\%)$ & $\mathbf{F a}$ & $\operatorname{Fr}(\%)$ & $\mathbf{F a}$ & $\operatorname{Fr}(\%)$ & Fa & $\operatorname{Fr}(\%)$ & \\
\hline Cerambycidae & 9 & 3,0 & 1 & 0,2 & 0 & 0 & 0 & 0 & 10 \\
\hline Lyctidae & 0 & 0 & 0 & 0 & 15 & 6,5 & 1 & 0,1 & 16 \\
\hline Bostrichydae & 46 & 15,5 & 117 & 23,0 & 11 & 4,8 & 171 & 22,5 & 345 \\
\hline Buprestidae & 1 & 0,4 & 4 & 0,8 & 0 & 0 & 4 & 0,5 & 9 \\
\hline Platypodinae & 13 & 4,4 & 27 & 5,3 & 1 & 0,4 & 55 & 7,2 & 96 \\
\hline Scolytinae & 91 & 30,8 & 192 & 37,7 & 80 & 34,6 & 411 & 54,0 & 774 \\
\hline Outros insetos & 136 & 45,9 & 168 & 33,0 & 124 & 53,7 & 119 & 15,7 & 547 \\
\hline Total & 296 & 100 & 509 & 100 & 231 & 100 & 761 & 100 & 1797 \\
\hline
\end{tabular}


Nas coletas realizadas no interior da mata (Figura 2B) a família Bostrichidae apresentou uma ligeira queda a partir do mês de julho. Flechtamnn et al. (1995) relataram picos populacionais para a família Scolytinae em plantios de pinheiros tropicais, obtido em período de menor temperatura nos meses de março, abril, maio, agosto e setembro.

As famílias coletadas no ambiente bordadura da mata (Figura 2A) apresentaram comportamento constante, com pouca variação mensal para o período avaliado, à exceção da subfamília Scolytinae, que apresentou um pico no mês de agosto. Possivelmente, essa alteração resultou de alteração do ambiente no entorno. Nas proximidades da bordadura, neste mês de agosto, ocorreu limpeza de pasto, com corte de algumas pequenas árvores, o que exalou compostos químicos, atraindo mais insetos desta subfamília.
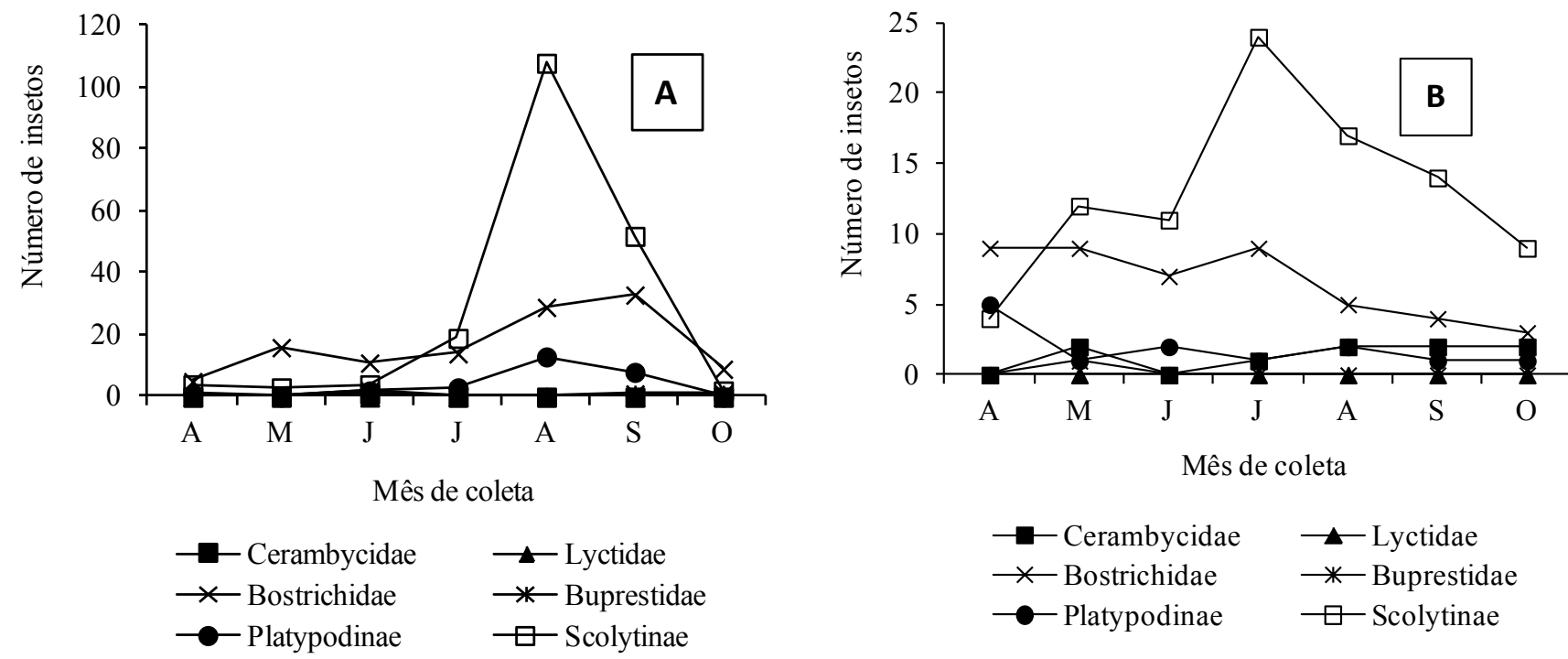

Figura 2. Flutuação populacional de coleópteros coletados com armadilhas modelo Carvalho-47 adaptado, instaladas na borda (A) e interior (B) do fragmento da Mata Atlântica, durante o período de abril a outubro de 2009.

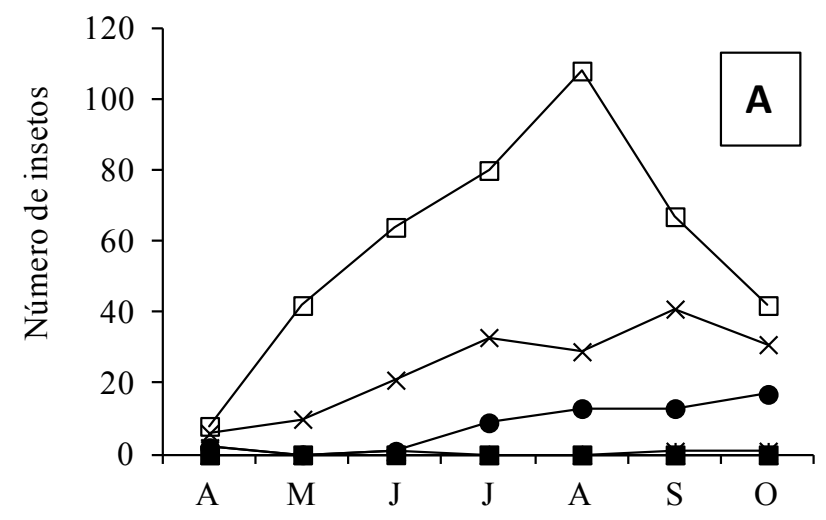

Mês de coleta

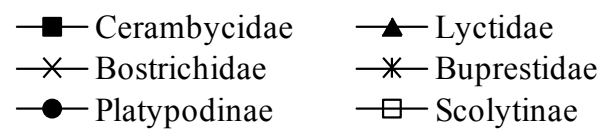

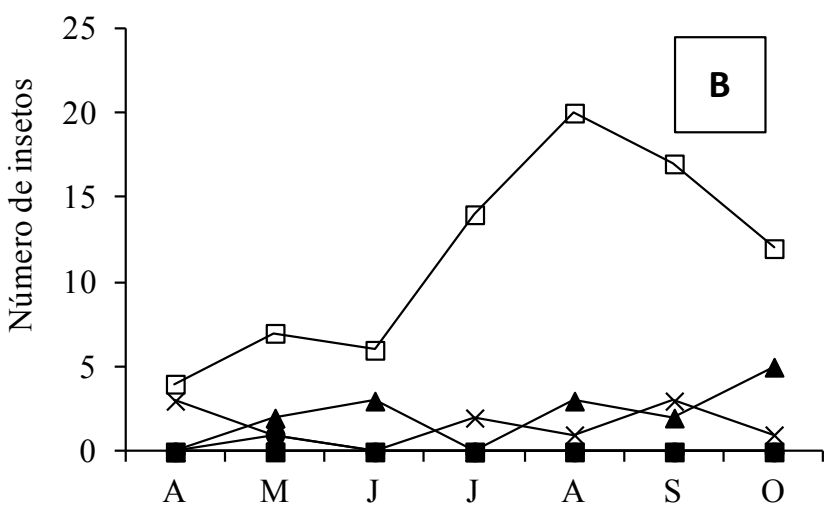

Mês de coleta

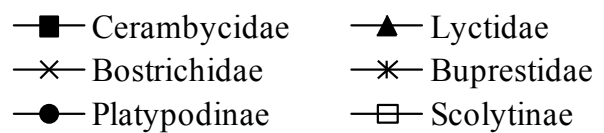

Figura 3. Flutuação populacional de coleópteros coletados com armadilha modelo Carvalho-47 adaptado, instalada na borda (A) e no interior (B) do talhão de Eucalyptus urophylla x Eucalyptus grandis durante o período de abril a outubro de 2009. 
Os escolytineos apresentaram um valor $15 \%$ menor ao encontrado por Carvalho et al. (1996) em floresta natural no Município de Seropédica, RJ. Oliveira et al. (2001) estudando os coleópteros associados a E. grandis encontraram poucos insetos das famílias Cerambycideae, Lycidae e subfamília Scolytinae para a mesma época do ano, nos anos de 1994 a 1995, no Município de Nova Era, MG. A subfamília Scolytinae também foi encontrada por Oliveira et al. (2001) em povoamentos de Eucalyptus grandis, utilizando armadilhas luminosas. Porém, os resultados obtidos por esses autores para a subfamília Scolytinae foi muito baixo, representando apenas $0,05 \%$ dos insetos coletados para um período de um ano, muito inferior ao observado no presente estudo $(43,07 \%)$, apesar do curto período de observação e coleta.

Nota-se que as armadilhas instaladas nos ambientes interiores apresentam um comportamento similar para os insetos classificados como outros insetos, para os meses mais frios (junho a setembro), indicando haver uma tendência dos mesmos procurarem ambientes de menor perturbação.

A frequência mais elevada da subfamília Scolytinae e da família Bostrichidae, para a bordadura no talhão de eucalipto pode ser explicada pela abertura de uma estrada ao longo do mesmo para sua colheita, havendo desta forma corte de alguns exemplares de eucalipto, contribuindo para maior atratividade dos insetos. As árvores foram retiradas do local logo após o corte, porém, o fato de haver exposição de compostos fenólicos e alcoóis contribuiu para atrair os insetos para as armadilhas (Flechtmann \& Gaspareto, 1997). Silva (2012) menciona que qualquer distúrbio que torne o hospedeiro mais susceptível pode levar a um repentino e significante aumento na população destas coleobrocas.

Os meses de agosto, setembro e julho foram os mais representativos em número total de insetos coletados, nas famílias/subfamílias estudadas, sendo respectivamente de $209(16,7 \%), 350(28,0 \%)$ e $259(20,7 \%)$. Os ambientes eucalipto borda e mata borda apresentaram os maiores números quantitativos de insetos coletados para o período (761 e 509 respectivamente), seguidos dos ambientes mata interior (296) e eucalipto interior (231), representando, respectivamente, $42,35 \%, 28,32 \%, 16,47 \%$ e $12,85 \%$ dos insetos, sendo que o ambiente eucalipto apresentou um montante de 55,21\% para os insetos coletados.

O número de insetos (547) classificados como outros insetos representaram praticamente $1 / 3$ de todos os insetos coletados nas áreas estudadas, o que é um indicativo positivo de diversidade e merecedor de estudo mais detalhado, principalmente a nível de espécie.

O maior número de insetos coletados para o período estudado foi representado pela subfamília Scolytinae. A grande quantidade de escolytineos coletados pode ser considerada preocupante, uma vez que são mencionados na literatura como vetores de diversas doenças em espécies florestais. Por outro lado, são também considerados como bioindicadores de diversidade e de recuperação de florestas (Berti Filho, 1979; Muller \& Andreiv, 2004; Zanuncio et al., 2005). A família Bostrichidae demonstrou também ser importante para a região estudada, por ser uma coleobroca que pode apresentar perfurações em madeira serrada, ficando em segundo lugar no número de insetos coletados. Estas perfurações podem comprometer a qualidade da madeira, reduzindo seu valor comercial.

Sugere-se que estudos de monitoramento da flutuação populacional de insetos sejam conduzidos por período mais longo, buscando-se o entendimento da sazonalidade da frequência intra e inter anual dos coleópteros broqueadores em diferentes sítios.

\section{Referências}

ABREU, R. L. S.; FONSECA, C. R. V.; MARQUES, E. N. Análise das principais espécies de Scolytidae coletadas em floresta primária no Estado do Amazonas. Anais da Sociedade Entomológica Brasileira, v. 26, n. 3, p. 527-53, 1997.

BERTI FILHO, E. Coleópteros de importância florestal: Scolytidae. IPEF, Piracicaba, v. 19, p. 39-43, 1979.

CARvalho, A. G. Armadilha modelo Carvalho-47. Floresta e Ambiente, Rio de Janeiro, RJ, v. 5, n. 1, p. 225-227, 1998.

CARVAlHO, A. G.; ROCHA, M. P.; SILVA, C. A. M.; LUNZ, A. M. Variação sazonal de Scolytidae (Coleoptera) numa comunidade de floresta natural de Seropédica, RJ. Floresta e Ambiente, Rio de Janeiro, RJ, v. 3, n. 1, p. 9-14, 1996.

DORVAL, A.; PERES FILHO, O.; MARQUES, E. N. Levantamento de Scolytidae (Coleoptera) em plantações de Eucalyptus spp. em Cuiabá, estado de Mato Grosso. Ciência Florestal, Santa Maria, RS, v. 14, n. 1, p. 47-58, 2004.

FERRAZ, F. C.; CARVALHO, A. G.; COUTINHO, C. L.; SOUZA, N. J. Eficiência de armadilhas etanólicas para levantamento de coleópteros do reflorestamento de Eucalyptus citriodora em Pinheiral, RJ. Floresta e Ambiente, Rio de Janeiro, RJ, v. 6, n. 1, p. 159-162, 1999.

FERREIRA FILHO, P. J.; WILCKEN, C. F.; COUTO, E. B.; OTTATI, A. L. T. Estudo da comunidade de escolitídeos (Coleóbroca: Scolytidae) em florestas de Eucalyptus grandis na região de Capão Bonito, SP. In: REUNIÃO CIENTÍFICA EM CIÊNCIAS AGRÁRIAS DO LAGEADO, 2002. Resumos... Botucatu: Faculdade de Ciências Agronômicas, UNESP, 2002. 22 p. 
FLECHTMANN, C.A.H.; COUTO, H.T.Z. do; GASPARETO, C.L.; BERTI FILHO, E. Manual de pragas em florestas Scolytidae em reflorestamento com pinheiros tropicais. Piracicaba: IPEF, 1995. 201 p. (IPEF. Manual de pragas em florestas, 4).

FLECHTMANN, C. A. H.; GASPARETO, C. L. Scolytidae em pátio de serraria da fábrica Paula Souza (Botucatu/SP) e fazenda Rio Claro (Lençois Paulista/SP). Scientia Forestalis, Piracicaba, v. 51, n. 2, p. 61-75, 1997.

FLECHTMANN, C. A. H.; GASPARETO, C. L.; TEIXEIRA, E. P. Levantamento populacional de Bostrichidae (Coleoptera) em área de cerrado na região de Agudos, SP. Revista Instituto Florestal, São Paulo, SP, v. 8, n. 1, p. 45-50, 1996.

GUSMÃO, R. S. Analise faunística de Scolytidae (Coleoptera) coletadas com armadilhas etanólicas com e sem porta isca em Eucalyptus ssp em área de cerrado no município de Cuiabá MT. 2011. 47 f. Dissertação (Mestrado em Ciências Florestais e Ambientais) - Universidade Federal de Mato Grosso, Cuiabá.

LELIS, A. T. Insetos deterioradores de madeira no meio urbano. Série Técnica: IPEF, Piracicaba, v. 13, n. 33, p. 81-90, 2000.

MARQUES, E. N. Scolytidae e Platypodidae em Pinus taeda. 1984. 65 f. Dissertação (Mestrado em Ciências) - Universidade Federal do Paraná, Curitiba.

MULLER, J. A.; ANDREIV, J. Caracterização da família Scolytidae (Insecta: Coleoptera) em três ambientes florestais. Cerne, Lavras, v. 10, n. 1, p. 39-45, 2004.
MURARI, A. B.; COSTA, E. C.; BOSCARDIM, J.; GARLET, J. Modelo de armadilha etanólica de interceptação de voo para captura de escolitídeos (Curculionidae: Scolytinae). Pesquisa Florestal Brasileira, Colombo, v. 32, n. 69, p. 115-117, 2012. DOI: 10.4336/2012.pfb.32.69.115

OLIVEIRA, H. G.; ZANUNCIO, T. V.; ZANUNCIO, J. C.; SANTOS, G. P. Coleópteros associados à eucaliptocultura na região de Nova Era, Minas Gerais, Brasil. Floresta e Ambiente, Rio de Janeiro, RJ, v. 1, p. 52-60, 2001.

PELENTIR, S. C. S. Eficiência de cinco modelos de armadilhas etanólicas na coleta de coleóptera: Scolytidae, em floresta nativa no município de Itaara, RS. 2007. 81 f. Dissertação (Mestrado em Engenharia Florestal) - Universidade Federal de Santa Maria, Santa Maria, RS.

SILVA, C. O. Ocorrência de Scolytinae no ambiente e na madeira de cinco espécies florestais em manguezal. 2012. 42 f. Dissertação (Mestrado em Ciências) - Universidade Federal Rural do Rio de Janeiro, Seropédica.

TREVISAN, H.; MARQUES, F. M. P.; CARVALHO, A. G. Degradação natural de toras de cinco espécies florestais em dois ambientes. Floresta, Curitiba, v. 38, n. 1, p. 33-42, 2008.

ZANUNCIO, J. C.; SOSSAI, M. F.; FLECHTMANN, C. A. H.; ZANUNCIO, V. Z.; GUIMARÃES, E. M.; ESPINDULA, M. C. Plants of an Eucalyptus clone damage by Scolytidae em Platypodidae (Coleoptera). Pesquisa Agropecuária Brasileira, Brasília, DF, v. 40, n. 5, p. 513-515, 2005. 